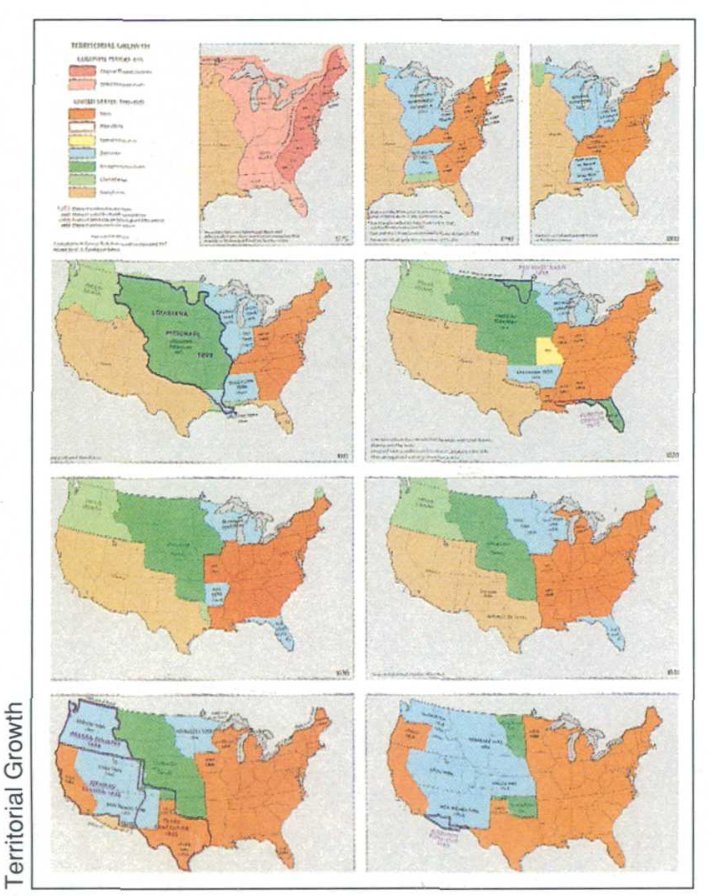

The National Atlas of the United States of America was published by the U.S. Geological Survey in 1970. Its 765 maps and charts are on 335 14- by 19inch pages. Many of the maps span facing pages.

It's worth a quick trip to the library just to leaf through all 335 pages of this book. Rapid scanning of its thematic maps yields rich insights to the geographic aspect of issues of continuing national interest. On most maps, the geographic patterns are still valid, though the data are not current.

The atlas is out of print, but many of its maps can be purchased separately. Maps that span facing pages in the atlas are printed on one sheet. The maps dated after 1970 are either revisions of original atlas maps, or new maps published in atlas format. The titles of the separate maps are listed here.

\section{Thematic maps of the United States}

Sheet size is 28 by 19 inches. Most of the maps have a scale of 1:7,500,000, but a few have scales that range between 1:17,000,000 and 1:34,000,000. Most of the maps include thematic data on the conterminous United States, Alaska, and Hawaii.

Climate

Annual Sunshine, Evaporation,

and Solar Radiation (1969)

Monthly Average Temperature (1965)

Monthly Maximum Temperature (1965)

Monthly Minimum Temperature (1965)

Monthly Sunshine (1965)

\section{Coastal environment}

Coastal Erosion and Accretion (1985)

Coastal Hazards (1985)

Ecology

National Wild and Scenic Rivers System (1990)

National Wilderness Preservation System (1987)

(Sheet size 42 by 28 inches; scale 1:5,000,000)

Networks of Ecological Research Areas (1983)

Principal Federal Lands Where Exploration

and Development of Mineral Resources are Restricted (1981)

Geology

Engineering Aspects of Karst (1984)

Geology (1966)

Surficial Geology (1979)

Tectonic Features (1967)

Tectonic Features [Alaska] (1968)

\section{Hydrology}

Surface Water (1965) (1988)

Political history and administration

Congressional Districts for the 100th

Congress (1987)

Counties (1987)

Federal Lands (1968)

Territorial Growth (1986)

Presidential Elections, 1789-1968/1972-1984

Electing the President, 1789-1988 (map booklet)

Presidential Election of 1988 (1989)

Electing the President 1789-1992 (map poster)

\section{Population}

Early Indian Tribes, Culture Areas,

and Linguistic Stocks (1967)

Population Distribution, Urban and Rural: 1960

Population Distribution, Urban and Rural: 1970

Population (1970)

\title{
National Atlas Maps
}

U.S. Department of the Interio

U.S. Geological Survey

nformation Center (ESIC)

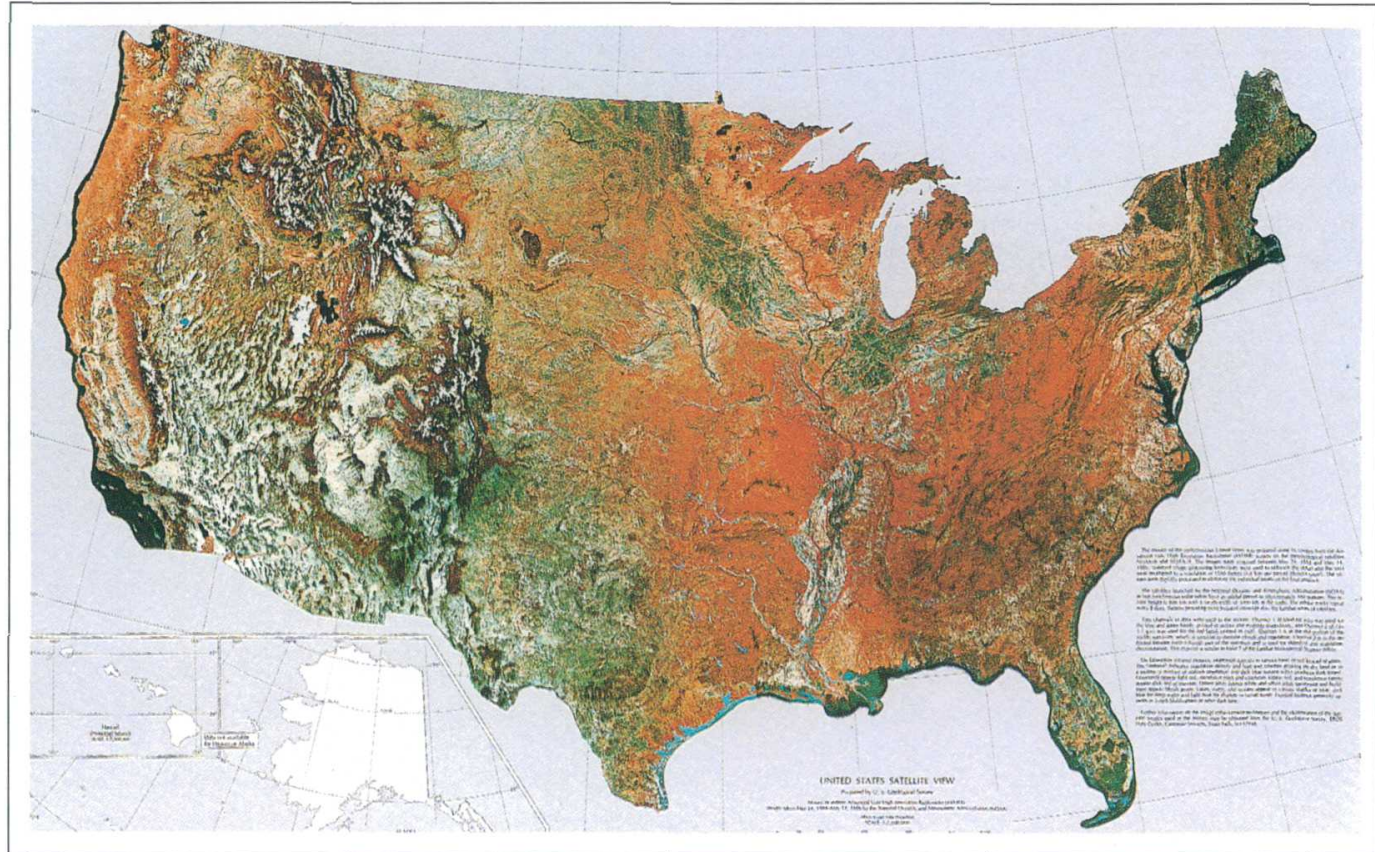

U.S. Satellite View (1990)

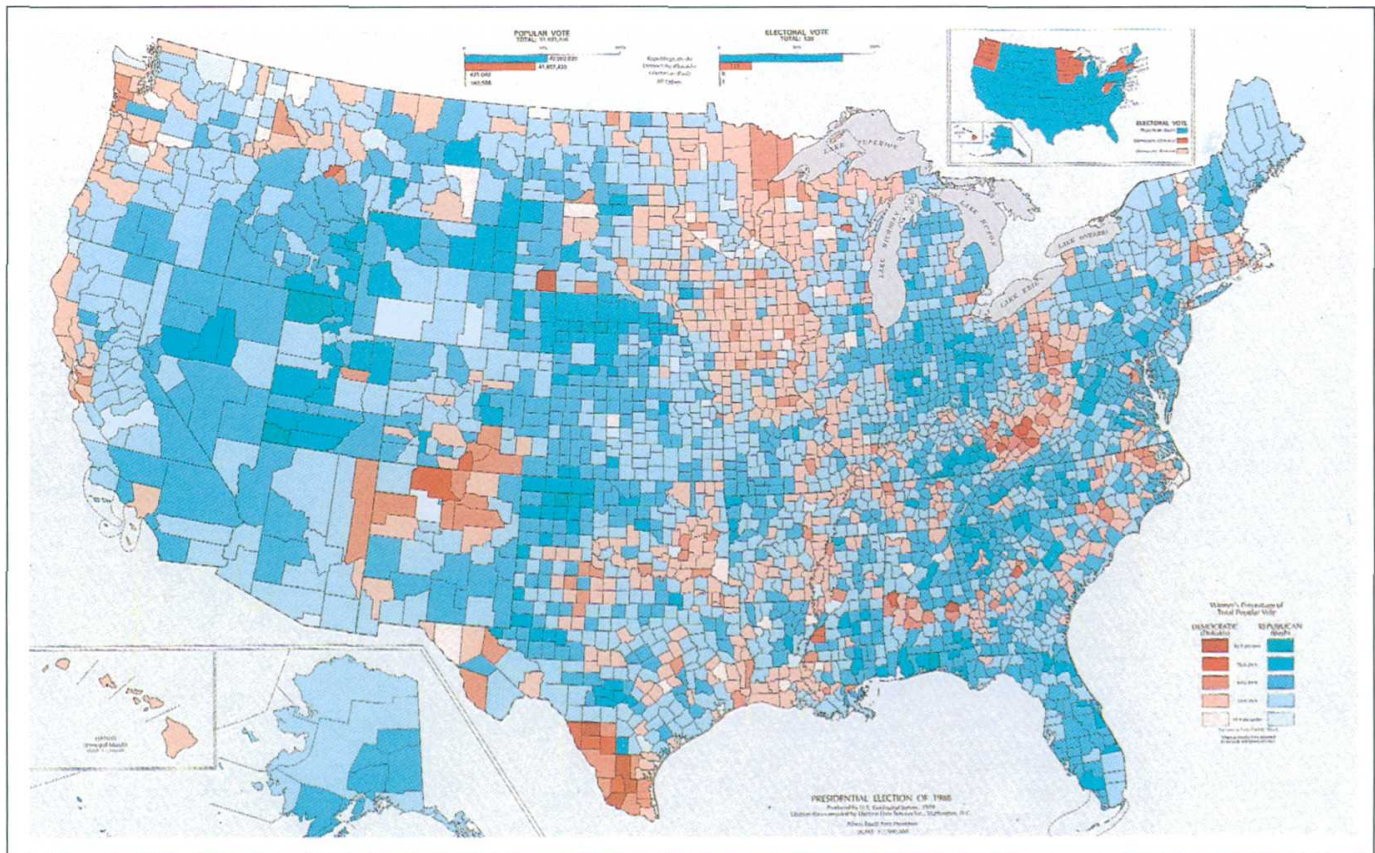

Presidential Election of 1988 (1989)

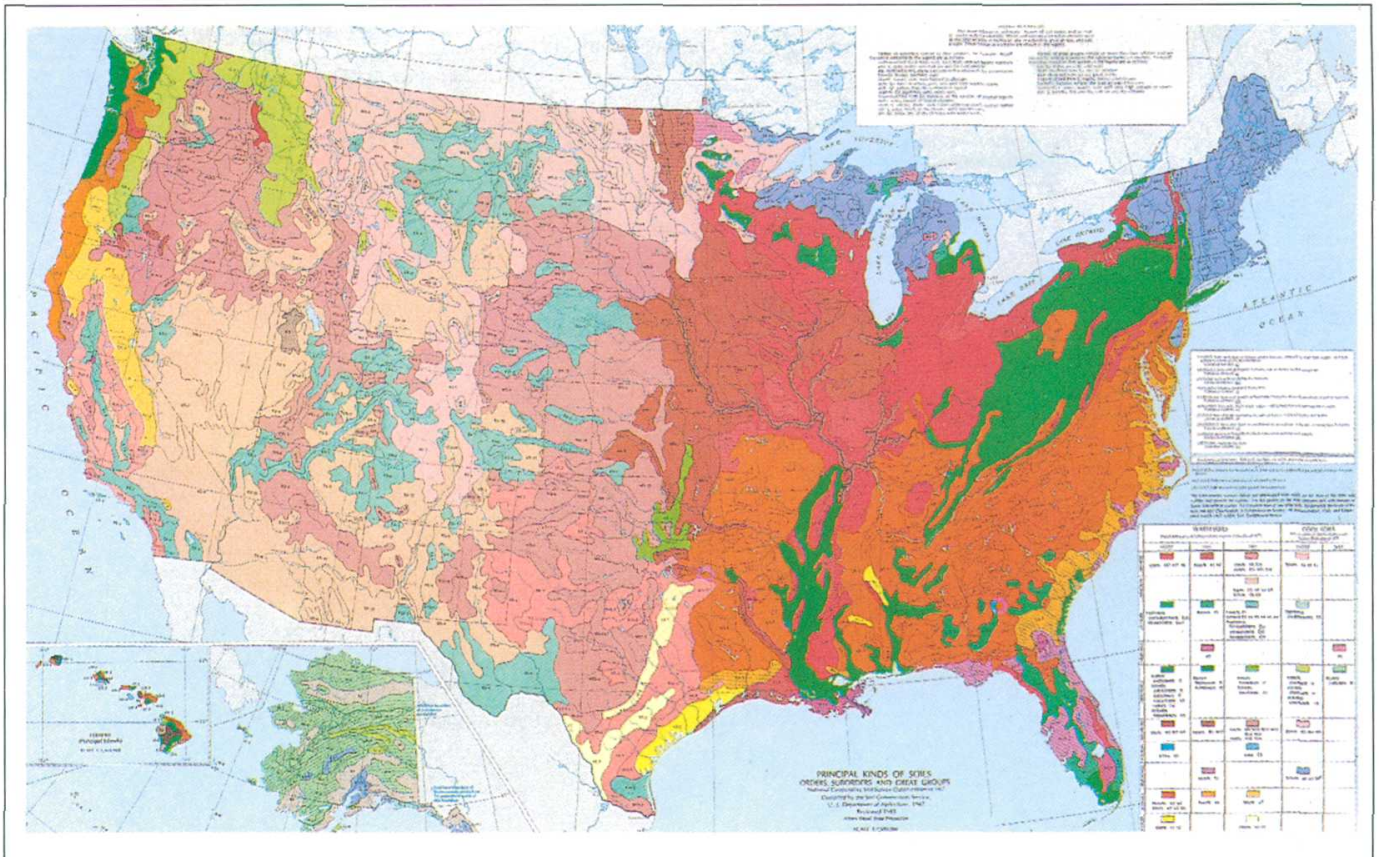


Thematic maps of the United States (continued)

\section{Recreation}

Outdoors America/Federal Recreation Lands (1992)

\section{Relief and physiograph}

Alaska Shaded Relief (1969)

Classes of Land-Surface Form (1964)

Land-Surface Form [Alaska] (1968)

Physiography and Physiographic Divisions (1968)

United States Shaded Relief (1969)

U.S. Satellite View (1990)

\section{Soils and vegetation}

Major Forest Types (1987, revisions to Alaska only) Potential Natural Vegetation (1985)

Soils (1985)

\section{Transportation}

Highways (1987)

\section{National Energy Transportation Maps}

This series of 19 thematic maps was prepared by the U.S. Geological Survey and originally published as part of a report by the Committee on Energy and Natural Resources and the Committee on Commerce, Science, and Transportation, U.S. Senate.

The transportation data were provided by the Congressional Research Service, Library of Congress.

The maps are in National Atlas thematic map format.

Coal Movement by Highways (1974) Coal Movement by Railroads (1974) Coal Movement by Water (1974)

Coal Resources and Distribution (1974)

Total Coal Movement (1974)
Crude Oil Movement by Pipelines (1974) Crude Oil Movement by Water (1974)

Total Crude Oil Movement (1974)

Electric Power Transmission (1974)

Natural Gas Movement by Pipelines (1974)

Nuclear Fuel Materials Movement by Highways (BTU) (1975)

Nuclear Fuel Materials Movement by Highways (Truckloads) (1975)

Petroleum Products Movement by Pipelines (1974)

Petroleum Products Movement by Water (1974)

Total Petroleum Movement (1974)

Total Petroleum Products Movement (1974)

Pipeline Transportation Systems (1974)

Railroad, Highway, and Water Transportation

Systems (1974)

Total Interstate Energy Movement (1974)

\section{Reference maps}

U.S. General Reference (1973)

This 28 - by 19 -inch map shows-

- Names of populated places and railroads in black

- Areas of cities with populations of more than 1

million in yellow

- State boundaries and names highlighted in gray

- Highways and ferry routes in red

- Water features in blue

- Names of physical features and shaded relief base in brown

- The conterminous 48 States and Hawaii at a scale of 1:7,500,000 (one inch represents 118.4 miles) - Alaska at a scale of 1:17,000,000 (one inch represents 268.3 miles)

Also, available are transparent plastic overlays at various scales to permit overlaying reference information on thematic maps.

\section{Sectional reference maps}

A series of multicolor planimetric (no contours) maps (also available singly) shows the United States in 21 sections at a scale of 1:2,000,000 (1 inch represents 31.5 miles). Content is similar to that of the U.S. General Reference without shaded relief, but is portrayed in greater detail; national park and forest lands, wildlife refuges, and Indian reservations are also shown.

Except for Alaska, California, Montana, and Texas, the sectional maps have been designed so that each State is shown in its entirety on one sheet.

Each map is printed on one side of a

28- by 19 -inch sheet.

Central Alaska (1973)

Northern Alaska (1973)

Southeastern Alaska (1972)

Southwestern Alaska (1973)

Aleutian Islands (1973)

Arizona and New Mexico (1973)

Southern California (1973)

Florida (1972)

Hawaiian Islands (1972)

Middle Atlantic States (1972)

Pennsylvania, New Jersey, Delaware, Maryland, Virginia, West Virginia, Ohio

Central Mississippi Valley States (1972) Indiana, Illinois, Iowa, Missouri, Kentucky

Southern Mississippi Valley States (1972) Alabama, Mississippi, Louisiana, Arkansas, Tennessee

Northeastern States (1972)

Maine, New Hampshire, Vermont, New York,

Massachusetts, Connecticut, Rhode Island

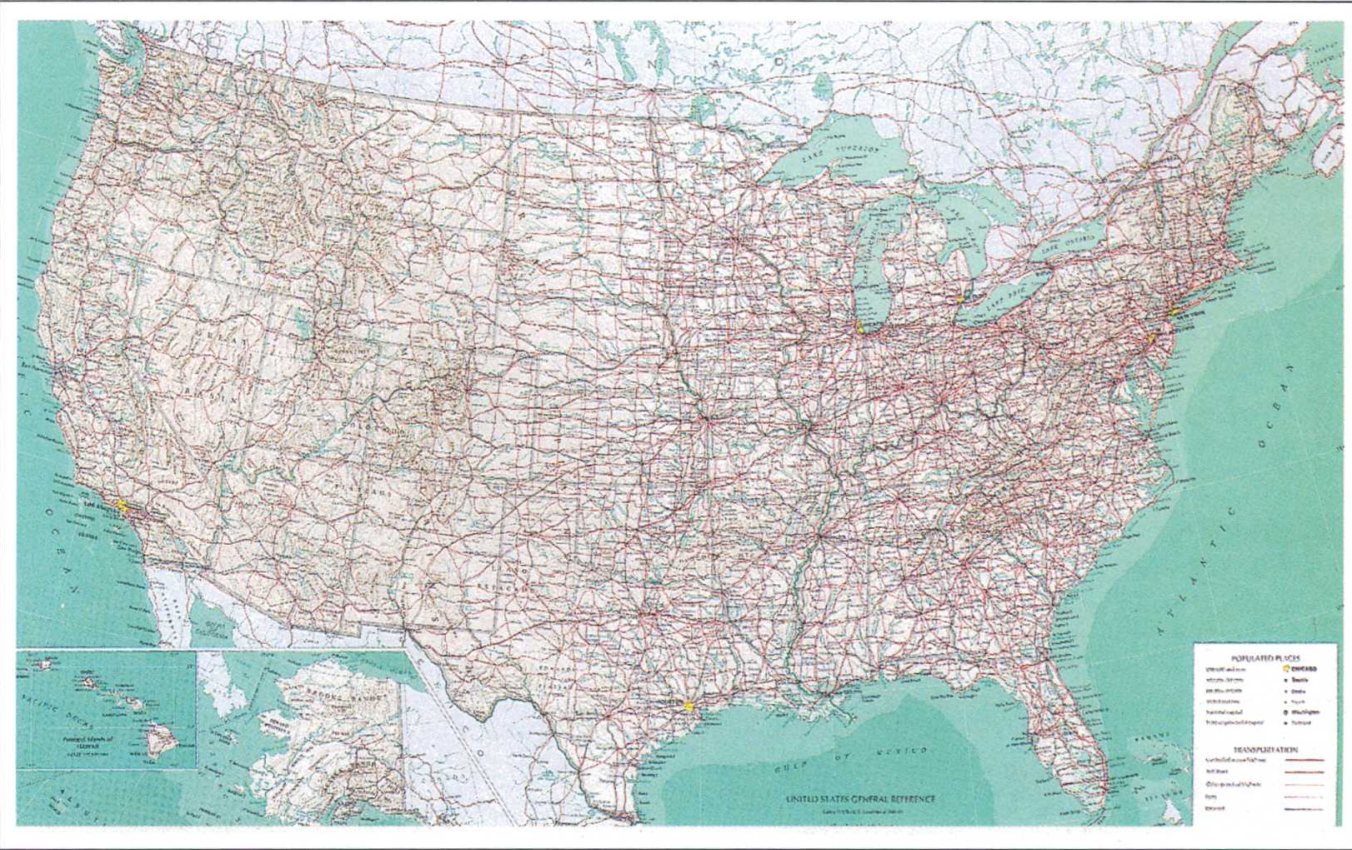

U.S. General Reference (1973)

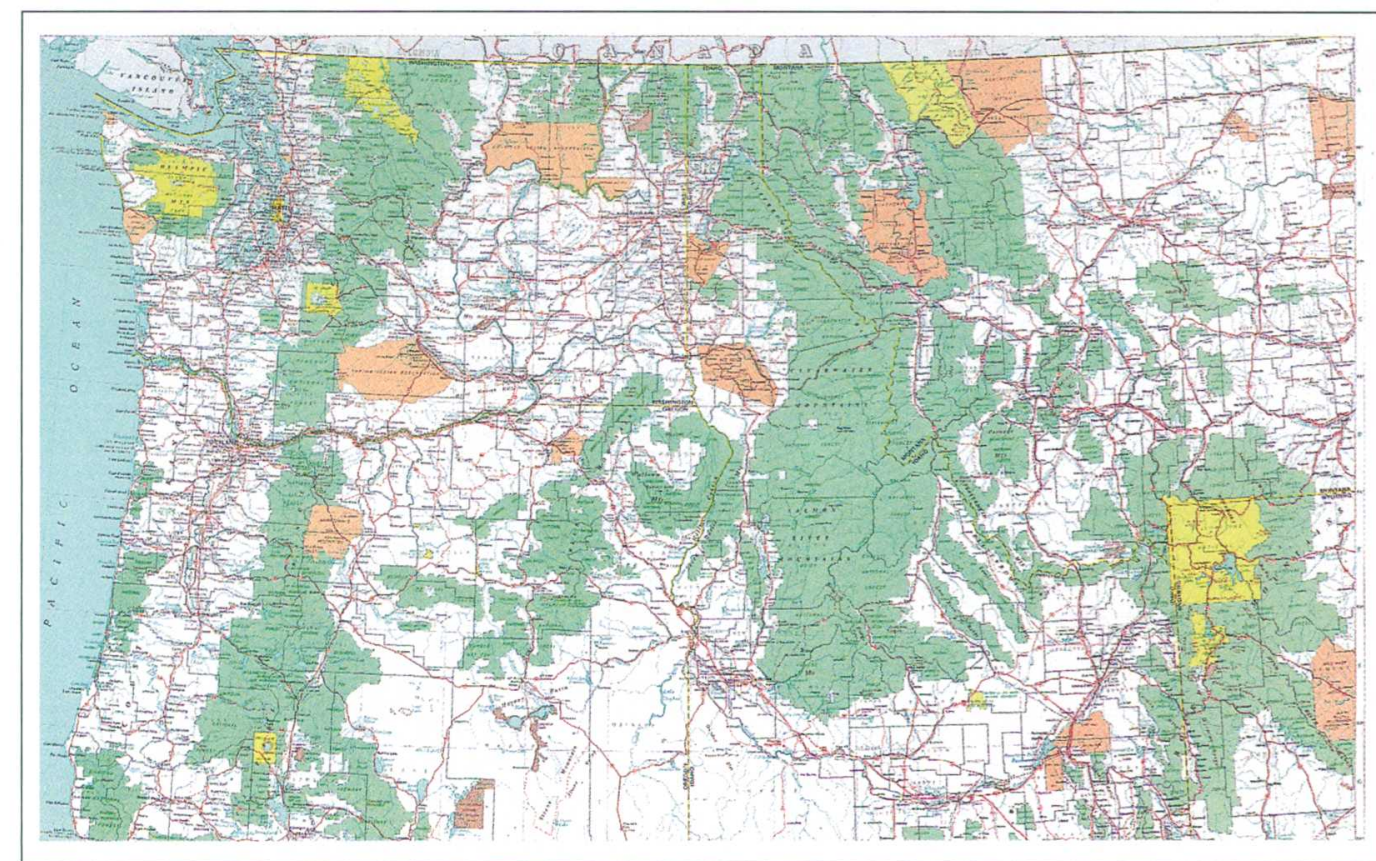

Northwestern States (1973)

Northern Great Lakes States (1972)

Michigan, Wisconsin, Minnesota

Northwestern States (1973

Western Montana, Idaho, Oregon, Washington

Central Pacific States (1972)

Northern California, Nevada, Utah

Central Plains States (1973)

Nebraska, Colorado, Kansas

Northern Plains States (1972)

North Dakota, South Dakota, Eastern Montana,

Wyoming

Southern Plains States (1973)

Oklahoma, Northern Texas

Southeastern States (1972)

North Carolina, South Carolina, Georgia

Southern Texas (1973)

\section{How to order National Atlas Maps}

To receive an order form and current list of all National Atlas Maps, contact any ESIC office, or call 1-800-USA-MAPS.

Maps of the United States published or distributed by the Geological Survey can be purchased from: USGS Map Distribution

Box 25286

Denver, CO 80225

(303) $236-7476$

Local and regional information about USGS maps and publications can be acquired from: 